\title{
Clinical Reasoning: A 57-Year-Old Man With Stepwise Progressive Paraparesis, Sensory Loss, Urinary Retention, and Constipation
}

Samir Alkabie, MD, MSc, Omar Tanweer, MD, George J. Hutton, MD, and Fernando X. Cuascut, MD, MPH

Neurology ${ }^{\circledR}$ 2022;98:e555-e560. doi:10.1212/WNL.0000000000013090
Correspondence

Dr. Alkabie

samiralkabie@gmail.com

\begin{abstract}
We present the case of a 57-year-old man with protein $S$ deficiency and left leg deep vein thrombosis (DVT) 5 years earlier, who developed stepwise progressive bilateral lower limb weakness, numbness/paresthesia, gait imbalance, hesitancy of micturition, and constipation in the setting of recurrent left common femoral DVT treated with apixaban. Symptoms amplified with Valsalva, corticosteroids, and postlumbar puncture, with longitudinally extensive midthoracic T2-hyperintense lesion extending to the conus associated with hazy holocord enhancement on magnetic resonance imaging (MRI), raising suspicion for spinal dural arteriovenous fistula (sDAVF). Initial digital subtraction angiography (DSA) was negative for sDAVF. However, cerebral spinal fluid (CSF) was herpes simplex virus (HSV)-2 positive, and he was treated with antiviral therapy. Unfortunately, he continued to worsen despite treatment. Repeat neuroimaging 12 months after initial presentation demonstrated persistent lower thoracic/conus lesion in addition to cauda equina enhancement and subtle dorsal T2hypointense flow voids. We raised red flags (e.g., lack of clinical prodrome, no herpetic rash, no CSF pleocytosis, and rostral extent of the lesion) that suggested the HSV2 nucleic acid detection was perhaps unrelated to the neurologic syndrome. Given the high index of suspicion for sDAVF, we repeated spinal vascular imaging. Spinal MRA demonstrated dilated right dorsal perimedullary veins from T10 to T11. Repeat DSA revealed a right T10 sDAVF. Microsurgical treatment rather than embolization of the fistula was successful without complication, with significant improvement in motor, sphincter, and to a lesser extent sensory function, with residual gait imbalance after inpatient rehabilitation 3 weeks postoperatively.
\end{abstract}

From the Maxine Mesinger Multiple Sclerosis Comprehensive Care Center (S.A., G.J.H., F.X.C.) and Departments of Neurology and Neurosurgery (O.T.), Baylor College of Medicine, Houston, TX.

Go to Neurology.org/N for full disclosures. Funding information and disclosures deemed relevant by the authors, if any, are provided at the end of the article.

See the Highlighted Changes supplement, showing the changes made in this updated version: http://links.Iww.com/WNL/C9. 


\section{Section 1}

A 57-year-old man with protein S deficiency and left leg DVT 5 years earlier presented with progressive bilateral lower limb weakness, numbness/paresthesia, gait imbalance, urinary hesitancy, and constipation, starting 3 weeks after the recurrence of left common femoral DVT treated with apixaban. Two weeks later, he had a low-speed motor vehicle accident (rear-ended). Over the next 2 months, these symptoms worsened in a stepwise manner, prompting hospitalization.

Neurologic examination revealed $4+/ 5$ hip flexion bilaterally, 4+/5 left knee flexion, spasticity, brisk patellar reflexes, bilateral Babinski sign, diminished pinprick, temperature, and vibratory sensation below the waist, and gait instability requiring a cane. MRI spine revealed a longitudinally extensive midthoracic T2-hyperintense lesion extending to the conus associated with hazy holocord enhancement (Figure 1, A-B). MRI of the brain showed nonspecific T2-hyperintensities. Given the concern for an idiopathic inflammatory condition and functional decline, he received intravenous methylprednisolone $1 \mathrm{~g} / \mathrm{d}$ for 3 days, worsening after infusions.

\section{Questions for Consideration:}

1. What is the anatomic localization?

2. What is the differential diagnosis?

Figure 1 Initial and Follow-up MRIs
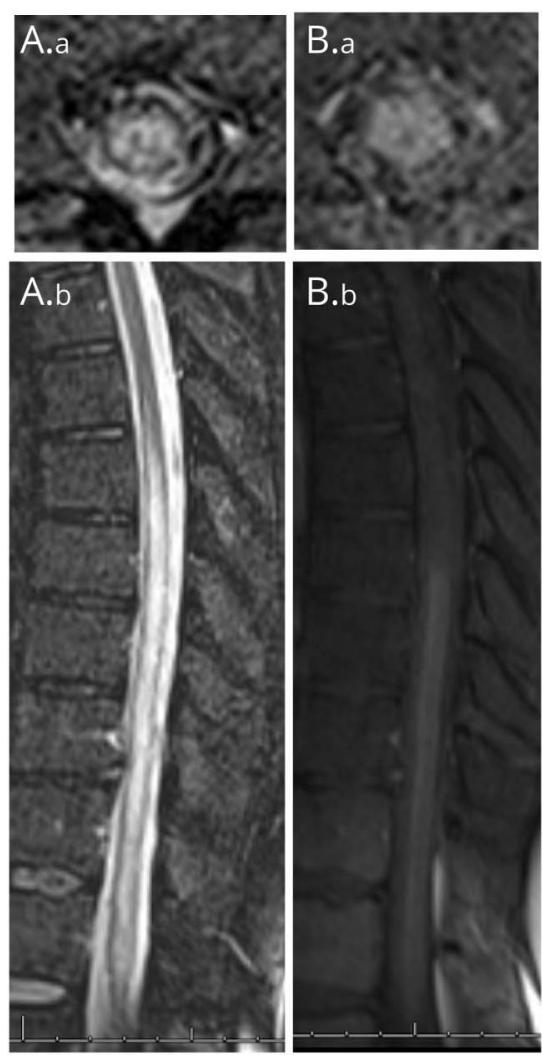
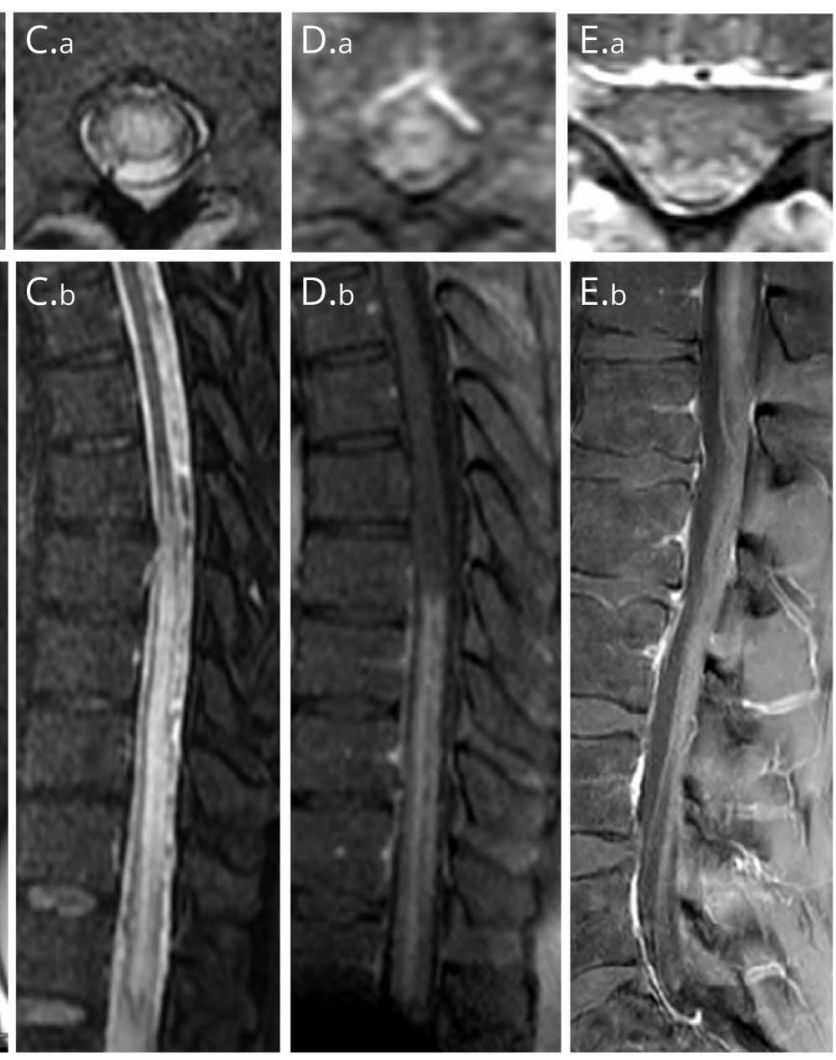

MRI findings approximately 4 months (A-B) and 12 months (C-E) after initial presentation demonstrates persistent longitudinally extensive T2-hyperintensity extending from T6-T7 to conus on sagittal STIR (A.b, C.b) throughout the central cord (A.a, C.a), with subtle flow voids (C.b). Hazy holocord gadolinium enhancement from T8-T9 to conus on sagittal (B.b, D.b) and axial (B.a, D.a) T1-weighted imaging. Cauda equina gadolinium enhancement on axial (E.a) and sagittal (E.b) view on T1-weighted postcontrast imaging. Axial images (A.a, B.a, C.a, D.a) were captured at T10-T11 and (E.a) at L4. 


\section{Section 2}

Lower limb motor function disturbance with upper motor neuron (UMN) signs implies bilateral corticospinal tract involvement below $\mathrm{T} 1$ level. ${ }^{1}$ The sensory level below the waist (L1) suggests a lesion at approximately $\mathrm{T} 10$, as spinothalamic fibers ascend the Lissauer tract by approximately 3 segments before they decussate. Disruption of all sensory modalities suggests a relatively large central cord lesion, involving spinothalamic and dorsal column tracts. ${ }^{1}$ Gait imbalance may be due to impaired conduction of lower limb proprioceptive information along spinocerebellar and gracile fasciculus tracts. ${ }^{2,3}$ Sphincter dysfunction of bladder and bowel results from interruption of afferent feedback of distension from these organs that normally triggers voiding, ${ }^{2}$ most commonly manifesting in hesitancy of micturition and constipation. ${ }^{3}$ Funicular (central) pain is common with intramedullary (but not extradural) spinal cord lesions, related to spinothalamic and dorsal column tract dysfunction. ${ }^{3}$

Time from onset to nadir and imaging features help narrow the differential diagnosis for spinal cord disorders. Despite his inherited thrombophilia, spinal cord infarct was unlikely, given time to nadir greater than 12 hours and lack of T2-hyperintense 'owl eyes' pattern on axial view or adjacent vertebral body infarct. ${ }^{4}$ Likewise, the absence of flat 'pancake-like' disc of enhancement or spondylotic stenosis, tumor, or hematoma on imaging ruled out a compressive myelopathy. Multiple sclerosis (MS), aquaporin-4 (AQP4)-IgG-seropositive neuromyelitis optica spectrum disorder (NMOSD), and MOG antibody disease (MOGAD)-associated myelitis often reaches nadir between 1 and 21 days $^{5}$ Although our patient had periventricular and spinal cord lesions (dissemination in space), the periventricular lesions were not Dawson finger in appearance, and the spinal cord lesion was longitudinally extensive and central rather than short and subpial, atypical for MS. ${ }^{6}$ AQP4IgG NMOSD and MOGAD can both present with longitudinally extensive myelitis. However, AQP4-IgG seropositive myelitis is associated with severe deficits (e.g., paraplegia), tonic spasms, and patchy or ring enhancement, whereas MOGAD typically affects the central grey matter $(\mathrm{H}$ sign $)$ with faint or absent enhancement on imaging. Autoimmune connective tissue disease (e.g., sarcoidosis, Behçet, lupus, Sjögren) was less likely without systemic symptoms. ${ }^{5,7}$ Neurosarcoidosis may cause longitudinally extensive lesions, but lesions tend to be avidly enhancing with dorsal subpial and central canal predilection (trident sign). Supportive nucleic acid detection and serology may rule in infectious myelitis. Paraneoplastic myelopathies are rare and tend to cause lateral or dorsal tractspecific signal changes on imaging (tractopathy). ${ }^{5}$

Symptom progression beyond 21 days suggests a metabolic myelopathy (e.g., B12, copper, and vitamin E deficiency) or spinal dural arteriovenous fistula (sDAVF). ${ }^{5}$ The UMN pyramidal signs and sensory ataxia could suggest a subacute combined degeneration because of B12 or copper deficiency. Still, there was no dorsal inverted "V" appearance or lateral column involvement on axial T2 imaging. ${ }^{8}$ In an older patient, with progressive lower thoracic myelopathy involving the conus, with or without T2-hypointense flow voids, worsening with steroids, sDAVF must be investigated by spinal vascular imaging as early intervention to obliterate the fistula improves outcome. $^{4}$

\section{Question for Consideration:}

1. What are the next steps in evaluation and management?

GO TO SECTION 3 


\section{Section 3}

Initial digital subtraction angiography (DSA) was negative for sDAVF. CSF showed one white blood cell $(\mathrm{WBC}) / \mu \mathrm{l}, 4 \mathrm{red}$ blood cells $(\mathrm{RBC}) / \mu \mathrm{l}$, normal glucose $(57 \mathrm{mg} / \mathrm{dL})$, mildly elevated protein $(55 \mathrm{mg} / \mathrm{dL})$, no oligoclonal bands, negative cytology, and flow cytometry. He noticed substantial worsening after lumbar puncture. HSV2 PCR was positive in CSF, for which he received intravenous acyclovir for 2 weeks then oral valacyclovir for 2 weeks outpatient. Additional laboratory studies were negative for HSV1, varicella zoster virus (VZV), west Nile virus (WNV), enterovirus, Borrelia burgdorferi, human immunodeficiency virus (HIV), antinuclear antibody, myeloperoxidase antibody, proteinase 3, and lupus anticoagulant. B12 (490 mg/dL), folate $(11.6 \mathrm{mg} / \mathrm{dL})$, and vitamin $\mathrm{D}(23.6 \mathrm{mg} / \mathrm{dL})$ were normal.

Seven months later, he sought readmission for worsening paraparesis (4/5 on right and $4+/ 5$ on left with UMN distribution), gait imbalance requiring a walker, intensified lower extremity dysesthesia and numbness, and pronounced urinary retention and constipation, amplified by exertion. Imaging redemonstrated the lower thoracic/conus lesion (Figure 1, C-D) in addition to cauda equina enhancement (Figure 1E) and subtle flow voids (Figure 1C.b.). Nerve conduction studies and electromyography were normal. $\mathrm{He}$ started tamsulosin and finasteride for urinary retention and a bowel regimen for constipation. Repeat CSF studies demonstrated xanthochromia, 3,690 RBCs/ $\mu \mathrm{L}$, no WBCs, elevated protein $(70 \mathrm{mg} / \mathrm{dL})$, and normal glucose $(64 \mathrm{mg} / \mathrm{dL})$. Repeat HSV2 PCR was negative in CSF. Serum AQP4 and MOG antibody testing were negative. Paraneoplastic autoantibody (Mayo Clinic) panel was negative. He continued to worsen on outpatient follow-up (e.g., 3/5 lower limb weakness with UMN distribution).

\section{Questions for Consideration:}

1. What are additional diagnostic considerations?

2. What further testing can help make the diagnosis? 

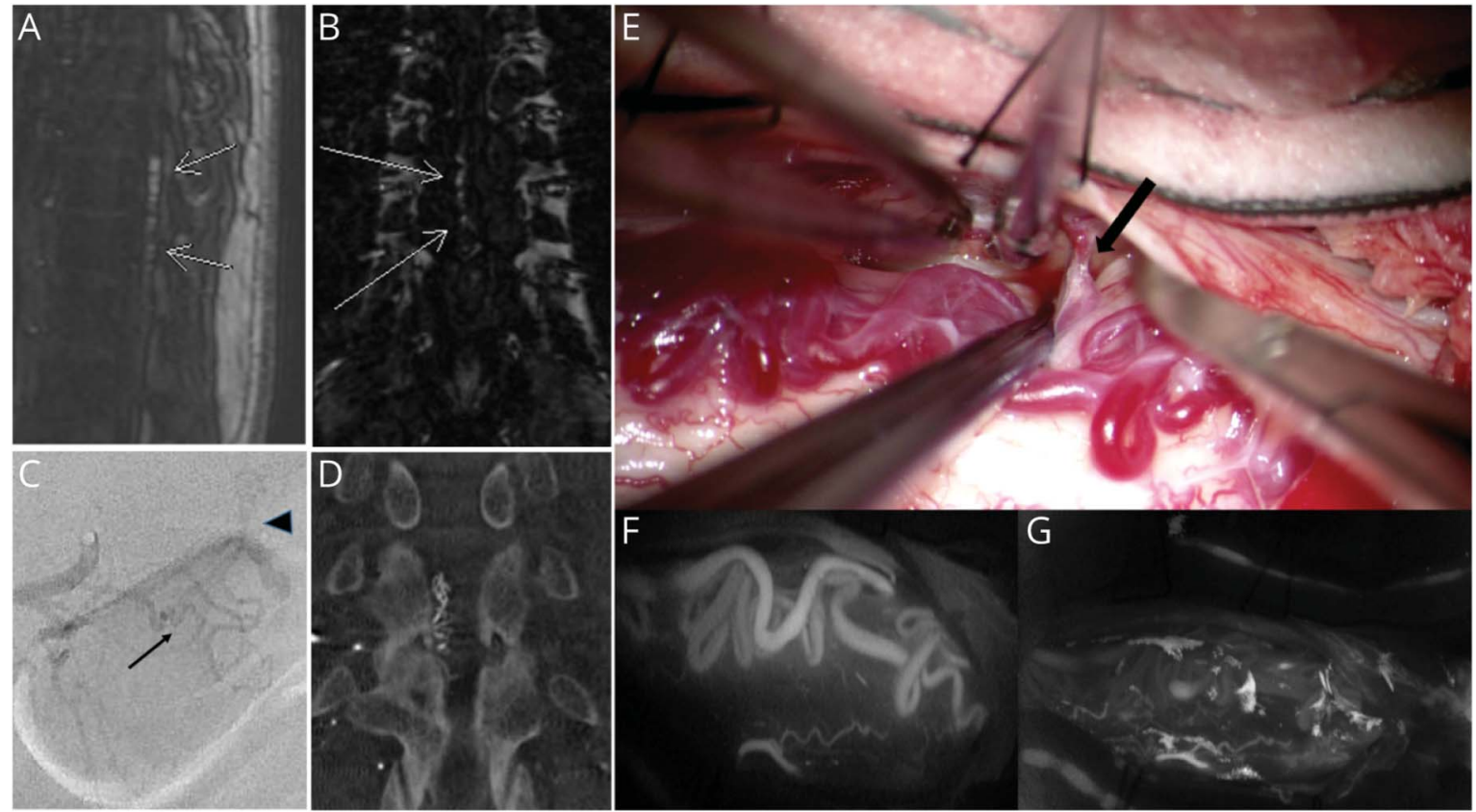

Spinal MRA demonstrates dilated right dorsal perimedullary veins from T10 to T11 on sagittal (A, arrows) and coronal (B, arrows) views. Digital subtraction angiography of the right T10 radicular artery showing the fistula (C, single arrow) leading to arterialized dorsal spinal veins (C, arrowhead). DynaCT during right T10 contrast injection showing similar findings (D). Intraoperative image of proximal arterialized vein exiting the fistula (E, arrow) and the engorged arterialized veins of the posterior aspect of the spinal cord. Intraoperative indocyanine green (ICG) infusion via intravenous route showing early arterial filling of the posterior spinal veins (F). Postsuccessful disconnection of the fistula with ICG infusion no longer showing early arterialized veins (G).

\section{Section 4}

Elsberg syndrome (ES) first described in the 1930s is a myeloradiculitis related to herpes infection (e.g., HSV-2 and VZV). ${ }^{9}$ Owing to rapid viral clearance, the highest yield for nucleic acid detection is 3-14 days after onset. ${ }^{10}$ HSV and VZV IgG index or IgM is preferred when CSF is obtained late. ${ }^{10}$ Savoldi et al. defined diagnostic criteria for ES and established exclusion criteria (e.g., myelitis rostral to T9) to distinguish ES from other mimics. Among patients with suspected ES and identified alternative diagnosis, 41 of 213 (19\%) had vascular myelopathy (sDAVF and infarction). ${ }^{10}$

We identified red flags arguing against ES in our patient. He had no history of herpetic rash, no CSF pleocytosis, inadequate antiviral treatment response, sequential rather than contemporaneous nerve root and spinal cord enhancement, and thoracic lesion rostral to T9, extending continuously rather than discontinuously to the conus. Owing to these red flags and a high index of suspicion for sDAVF, we recommended repeat angiography. Spinal MRA was initially preferred due to periprocedural risks (e.g., bleeding risk on apixaban) and demonstrated dilated right dorsal perimedullary veins from T10 to T11 (Figure 2, A-B). Repeat DSA revealed a right T10 sDAVF (Figure $2 \mathrm{C}$ ) confirmed by DynaCT (Figure 2D). Embolization seemed an unsafe option because of fistula location and risk of ischemic complication.
Microsurgical disconnection of the fistula was successful without complication (Figure 2, E-G), with significant improvement in motor/gait, sphincter, and to a lesser extent sensory function after inpatient rehabilitation 3 weeks postoperatively.

\section{Discussion}

sDAVF results from an acquired arteriovenous connection between a radiculomeningeal artery and vein, causing arterialization of the vein, venous hypertension, venous stasis, and spinal cord ischemia. ${ }^{4}$ Valsalva, corticosteroids, and lumbar puncture may worsen deficits by elevating venous pressure. ${ }^{4,11}$ Treatment is by endovascular embolization ( $80 \%$ efficacy) or microsurgical interruption of the fistula ( $98 \%$ efficacy). Early treatment may improve or stabilize neurologic deficits. Clinical severity before treatment predicts outcome. ${ }^{4}$ Although DSA is the gold standard for diagnosis, it is not perfect. In one study, 53 of 80 patients $(66 \%)$ received delayed diagnosis of sDAVF, of which $19 \%$ had previously normal angiogram. ${ }^{12}$ Atherosclerosis of segmental arteries and thrombosis or vasospasm of veins may negatively affect angiographic sDAVF detection. ${ }^{4}$

Trauma $^{4}$ or local venous occlusion ${ }^{3,13}$ may contribute to fistula development. Onset preceded any trauma in our patient by several weeks suggesting an atraumatic etiology. Disrupted outflow by venous occlusion may enlarge pre-existing vascular 
channels leading to incompetence of any valves and persistent arteriovenous shunt, even after thrombus resolution. Venous ischemia and vascular distension may also induce the release of angiogenic factors, vascular endothelial growth factor (VEGF), and hypoxia-inducible factor-1 (HIF-1) that promote collateralization. ${ }^{14}$ Whether indolent HSV2 angiopathy promotes SDAVF development is unknown. Yet, the positive predictive value of viral PCR is imperfect $(\sim 54 \%) .{ }^{15}$ Viral nucleic acid detection in CSF may be unrelated to the neurologic disorder.

Identifying imaging patterns may improve early detection and outcome. In one study of 44 patients with sDAVF and intraparenchymal enhancement, 19 (43\%) exhibited the missing-piece sign, defined by at least one nonenhancing area within a long segment of holocord enhancement. ${ }^{12} \mathrm{We}$ detected a mismatch between the length of T2-hyperintensity and enhancement, rather than the missing-piece sign. Better contrast egress in nonenhancing portions of lesion underlies this finding. Spinal MRA can be helpful in indirectly locating the fistula by demonstrating dilated perimedullary veins with a sensitivity of $80 \%-95 \% .{ }^{4}$ In our patient, spinal MRA helped localize the level and laterality of the fistula within one segment.

\section{Study Funding}

The authors report no targeted funding.

\section{Disclosure}

The authors report no disclosures relevant to the manuscript. Go to Neurology.org/N for full disclosures.

\section{Appendix Authors}

\begin{tabular}{lll}
\hline Name & Location & Contribution \\
\hline Samir & Maxine Mesinger Multiple & Drafting/revision of the \\
Alkabie, & Sclerosis Comprehensive & manuscript for content, \\
MD, MSc & Care Center, Department of & including medical writing for \\
& Neurology, Baylor College of & content; major role in the \\
& Medicine, Houston, TX & $\begin{array}{l}\text { acquisition of data; study } \\
\text { concept or design; analysis or } \\
\text { interpretation of data }\end{array}$ \\
& & \\
\end{tabular}

Appendix (continued)

\begin{tabular}{|c|c|c|}
\hline Name & Location & Contribution \\
\hline $\begin{array}{l}\text { Omar } \\
\text { Tanweer, } \\
\text { MD }\end{array}$ & $\begin{array}{l}\text { Department of } \\
\text { Neurosurgery, Baylor } \\
\text { College of Medicine, } \\
\text { Houston, TX }\end{array}$ & $\begin{array}{l}\text { Drafting/revision of the } \\
\text { manuscript for content, } \\
\text { including medical writing for } \\
\text { content; major role in the } \\
\text { acquisition of data }\end{array}$ \\
\hline $\begin{array}{l}\text { George J. } \\
\text { Hutton, MD }\end{array}$ & $\begin{array}{l}\text { Maxine Mesinger Multiple } \\
\text { Sclerosis Comprehensive } \\
\text { Care Center, Department of } \\
\text { Neurology, Baylor College of } \\
\text { Medicine, Houston, TX }\end{array}$ & $\begin{array}{l}\text { Drafting/revision of the } \\
\text { manuscript for content, } \\
\text { including medical writing for } \\
\text { content; analysis or } \\
\text { interpretation of data }\end{array}$ \\
\hline $\begin{array}{l}\text { Fernando X. } \\
\text { Cuascut, } \\
\text { MD, MPH }\end{array}$ & $\begin{array}{l}\text { Maxine Mesinger Multiple } \\
\text { Sclerosis Comprehensive } \\
\text { Care Center, Department of } \\
\text { Neurology, Baylor College of } \\
\text { Medicine, Houston, TX }\end{array}$ & $\begin{array}{l}\text { Drafting/revision of the } \\
\text { manuscript for content, } \\
\text { including medical writing for } \\
\text { content; major role in the } \\
\text { acquisition of data; study } \\
\text { concept or design; analysis or } \\
\text { interpretation of data }\end{array}$ \\
\hline
\end{tabular}

\section{References}

1. Blumenfeld H. Neuroanatomy Through Clinical Cases, 2nd ed. Sinauer Associates, Inc.; 2018.

2. Hardy TA. Spinal cord anatomy and localization. Continuum. 2021;27(1):12-29.

3. Brazis PWMJ, Biller J. Localization in Clinical Neurology, 6th ed. Lippincott Williams \& Wilkins; 2011.

4. Zalewski NL. Vascular myelopathies. Continuum (Minneap MN). 2021;27(1 Spinal Cord Disorders):30-61.

5. Lopez Chiriboga S, Flanagan EP. Myelitis and other autoimmune myelopathies. Continuum (Minneap MN). 2021;27(1):62-92.

6. Thompson AJ, Banwell BL, Barkhof F, et al. Diagnosis of multiple sclerosis: 2017 revisions of the McDonald criteria. Lancet Neurol. 2018;17(2):162-173.

7. Krause MA, English SW, Zalewski NL. Clinical Reasoning: a 70-year-old man with rapid stepwise paraparesis and sensory loss. Neurology. 2020;94(6):e651-e655.

8. Parks NE. Metabolic and toxic myelopathies. Continuum (Minneap MN). 2021;27(1): 143-162.

9. Eberhardt O, Kuker W, Dichgans J, Weller M. HSV-2 sacral radiculitis (Elsberg syndrome). Neurology 2004;63(4):758-759.

10. Savoldi F, Kaufmann TJ, Flanagan EP, Toledano M, Weinshenker BG. Elsberg syndrome: a rarely recognized cause of cauda equina syndrome and lower thoracic myelitis. Neurol Neuroimmunol Neuroinflamm. 2017;4(1):e355.

11. Garcia-Cabo C, Moris G. Sudden paraplegia after lumbar puncture as a clue in the diagnosis of a patient with spinal dural arteriovenous fistula. Eur Spine J. 2017;26(suppl 1):151-153.

12. Zalewski NL, Rabinstein AA, Brinjikji W, et al. Unique gadolinium enhancement pattern in spinal dural arteriovenous fistulas. JAMA Neurol. 2018;75(12):1542-1545.

13. Ropper A, Martin AS, Klein JP. Adams and Victor's Principles of Neurology, 10th ed. McGraw-Hill Education; 2014.

14. Bhogal P, Yeo LL, Henkes H, Krings T, Soderman M. The role of angiogenesis in dural arteriovenous fistulae: the story so far. Interv Neuroradiol. 2018;24(4):450-454.

15. Davies NW, Brown LJ, Gonde J, et al. Factors influencing PCR detection of viruses in cerebrospinal fluid of patients with suspected CNS infections. J Neurol Neurosurg Psychiatry 2005;76(1):82-87. 


\section{Neurology}

\section{Clinical Reasoning: A 57-Year-Old Man With Stepwise Progressive Paraparesis, Sensory Loss, Urinary Retention, and Constipation \\ Samir Alkabie, Omar Tanweer, George J. Hutton, et al. \\ Neurology 2022;98;e555-e560 Published Online before print November 19, 2021 \\ DOI 10.1212/WNL.0000000000013090}

This information is current as of November 19, 2021

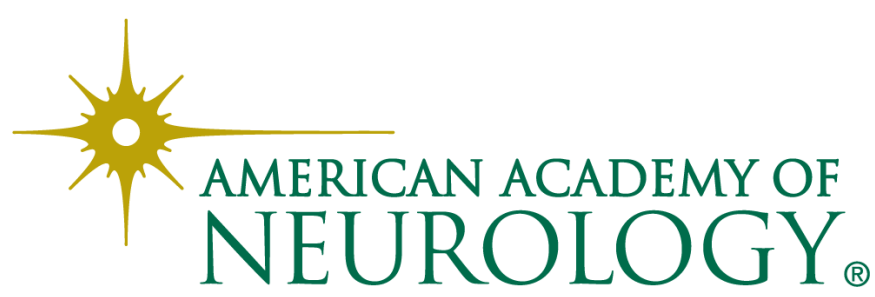




\section{Updated Information \& Services}

References

Citations

Subspecialty Collections

\section{Errata}

\section{Permissions \& Licensing}

Reprints including high resolution figures, can be found at: http://n.neurology.org/content/98/5/e555.full

This article cites 12 articles, 4 of which you can access for free at: http://n.neurology.org/content/98/5/e555.full\#ref-list-1

This article has been cited by 1 HighWire-hosted articles: http://n.neurology.org/content/98/5/e555.full\#\#otherarticles

This article, along with others on similar topics, appears in the following collection(s):

All Clinical Neurology

http://n.neurology.org/cgi/collection/all_clinical_neurology All Epilepsy/Seizures

http://n.neurology.org/cgi/collection/all_epilepsy_seizures

All Spinal Cord

http://n.neurology.org/cgi/collection/all_spinal_cord

Arteriovenous malformation

http://n.neurology.org/cgi/collection/arteriovenous_malformation

MRI

http://n.neurology.org/cgi/collection/mri

Status epilepticus

http://n.neurology.org/cgi/collection/status_epilepticus

Transverse myelitis

http://n.neurology.org/cgi/collection/transverse_myelitis

An erratum has been published regarding this article. Please see next page or:

/content/99/3/134.full.pdf

Information about reproducing this article in parts (figures,tables) or in its entirety can be found online at:

http://www.neurology.org/about/about_the_journal\#permissions

Information about ordering reprints can be found online:

http://n.neurology.org/subscribers/advertise

Neurology ${ }^{\circledR}$ is the official journal of the American Academy of Neurology. Published continuously since 1951, it is now a weekly with 48 issues per year. Copyright @ 2021 American Academy of Neurology. All rights reserved. Print ISSN: 0028-3878. Online ISSN: 1526-632X.

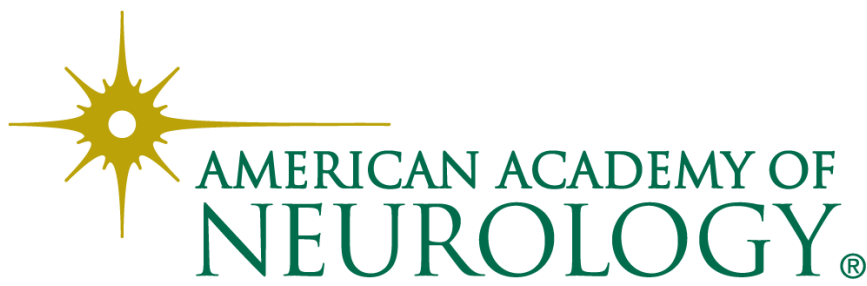




\section{Disputes \& Debates: Editors' Choice}

Steven Galetta, MD, FAAN, Editor

Aravind Ganesh, MD, DPhil, FRCPC, Deputy Editor

Ariane Lewis, MD, Deputy Editor

James E. Siegler III, MD, Deputy Editor

\section{Editors' Note: Long-term Effect of Regular Physical Activity and Exercise Habits in Patients With Early Parkinson Disease}

In "Long-term effect of regular physical activity and exercise habits in patients with early Parkinson disease," Tsukita et al. reported that average regular physical activity levels over time were associated with slower deterioration of gait stability, activities of daily living, and processing speed in patients with Parkinson disease (PD). Darweesh et al. contextualized these findings by noting they are consistent with the results of other studies, suggesting that regular exercise may slow progression of $\mathrm{PD}$. They further proposed that vigorous exercise may reduce the risk of $\mathrm{PD}$, implying that the findings of Tsukita et al. may also be attributed to reverse causality. Tsukita et al. agreed that reverse causality is feasible, although other data suggest that exercise may change the brain, modifying the course of PD. However, Gupta questioned the pathophysiologic mechanism by which exercise changes the brain and affects disease progression in PD, commenting that perhaps motivation to exercise may be relevant to disease progression in PD. In light of these comments, Tsukita et al. reinforced the need for the following types of future research: (1) international, multicenter randomized controlled trials on the effect of exercise on disease progression (for patients with PD) and development of clinical symptoms of PD (for patients with prodromal PD) which include neuroimaging; (2) evaluation of the motivation for patients with PD to exercise; and (3) animal studies on the effect of exercise on the brain, which include neuropathology assessment of $\alpha$-synuclein.

\section{Reader Response: Long-term Effect of Regular Physical Activity and Exercise Habits in Patients With Early Parkinson Disease}

Sirwan K.L. Darweesh (Nijmegen, the Netherlands), Nienke De Vries (Nijmegen, the Netherlands),

and Bastiaan R. Bloem (Nijmegen, the Netherlands)

Neurology ${ }^{\circledR}$ 2022;99:131-132. doi:10.1212/WNL.0000000000200922

The study by Tsukita et al. ${ }^{1}$ explores the prolonged benefits of vigorous exercise for patients with Parkinson disease over long intervals ( $>5$ years). This research builds on 2 recent trials, which demonstrate that engaging in vigorous exercise stabilizes the clinical progression of Parkinson disease (PD) over 6 months. ${ }^{2,3}$ The study also suggests that maintaining a high total volume of physical activities, even at low intensity, may yield additional benefits.

Because this was not a randomized controlled trial, some of the observed associations may reflect reverse causality. However, taken together with the results from animal models, previous observational studies, and 2 clinical trials, there is now converging evidence that regularly engaging in exercise may slow the progression of PD. ${ }^{4}$ This should not only motivate people with PD to be physically active but could also open up avenues for the prevention of PD. 
Prospective studies show that vigorous exercise and a high total volume of physical activities are both associated with a reduced risk of PD. ${ }^{5}$ A possible explanation is that exercise may slow the pathologic processes of $\mathrm{PD}$ already during the decade-long prodromal phase of the disease. The findings by Tsukita et al. should inspire intervention studies for patients suspected of having prodromal $\mathrm{PD}$, to determine whether regular exercise over long intervals may prevent or delay the manifestation of overt clinical symptoms of PD.

1. Tsukita K, Sakamaki-Tsukita H, Takahashi R. Long-term effect of regular physical activity and exercise habits in patients with early Parkinson disease. Neurology. 2022;98(8):e859-e871. doi: 10.1212/WNL.0000000000013218

2. van der Kolk NM, de Vries NM, Kessels RPC, et al. Effectiveness of home-based and remotely supervised aerobic exercise in Parkinson's disease: a double-blind, randomised controlled trial. Lancet Neurol. 2019;18(11):998-1008. doi: 10.1016/S1474-4422(19)30285-6

3. Schenkman M, Moore CG, Kohrt WM, et al. Effect of high-intensity treadmill exercise on motor symptoms in patients with de novo Parkinson disease: a phase 2 randomized clinical trial. JAMA Neurol. 2018;75(2):219-226. doi: 10.1001/jamaneurol.2017.3517

4. de Vries NM, Darweesh SKL, Bloem BR. Citius, fortius, altius-understanding which components drive exercise benefits in Parkinson disease. JAMA Neurol. 2021;78(12):1443-1445. doi: 10.1001/jamaneurol.2021.3744

5. Fang X, Han D, Cheng Q, et al. Association of levels of physical activity with risk of Parkinson disease: a systematic review and metaanalysis. JAMA Netw Open. 2018;1(5):e182421. doi: 10.1001/jamanetworkopen.2018.2421

Copyright @ 2022 American Academy of Neurology

\section{Author Response: Long-term Effect of Regular Physical Activity and Exercise Habits in Patients With Early Parkinson Disease}

Kazuto Tsukita (Kyoto, Japan), Haruhi Sakamaki-Tsukita (Kyoto, Japan), and Ryosuke Takahashi (Kyoto, Japan) Neurology ${ }^{\circledR}$ 2022;99:132. doi:10.1212/WNL.0000000000200923

We thank Darweesh et al. for their comment on our article. ${ }^{1}$ Because of the observational nature of our study, the possibility of reverse causality or that it reflects a symptomatic effect cannot be denied. However, in light of the recent highlighted evidence, ${ }^{2}$ it is quite possible that the results demonstrate the disease-modifying effects of physical activities. In addition to our study, a recent study showed that exercise may change the brain network to some extent, thus providing additional support for the possible disease-modifying effects of exercise and physical activities. $^{3}$

We hope that this study will motivate patients with Parkinson disease (PD) to keep engaging in physical activities and inspire future randomized clinical trials (RCTs) to focus on sustained exercise, for example, through remote supervision. ${ }^{2,4}$ We also hope that in the future those RCTs will include many ethnic groups through international multicenter studies, 5 and a way to modify the pathogenesis of PD and delay its onset through exercise and physical activities will eventually be found for patients with PD and "prodromal" subjects all over the world.

1. Tsukita K, Sakamaki-Tsukita H, Takahashi R. Long-term effect of regular physical activity and exercise habits in patients with early Parkinson disease. Neurology. 2022;98(8):e859-e871. doi:10.1212/WNL.0000000000013218.

2. de Vries NM, Darweesh SKL, Bloem BR. Citius, fortius, altius-understanding which components drive exercise benefits in Parkinson disease. JAMA Neurol. 2021;78(12):1443-1445. doi:10.1001/jamaneurol.2021.3744.

3. Johansson ME, Cameron IGM, Van der Kolk NM, et al. Aerobic exercise alters brain function and structure in Parkinson's disease: a randomized controlled trial. Ann Neurol. 2022;91(2):203-216. doi:10.1002/ana.26291

4. van der Kolk NM, de Vries NM, Kessels RPC, et al. Effectiveness of home-based and remotely supervised aerobic exercise in Parkinson's disease: a double-blind, randomised controlled trial. Lancet Neurol. 2019;18(11):998-1008. doi:10.1016/S1474-4422(19)30285-6.

5. Lau YH, Podlewska A, Ocloo J, et al. Does ethnicity influence recruitment into clinical trials of Parkinson's disease?. J Parkinsons Dis. 2022;12(3):975-981. doi:10.3233/JPD-213113.

Copyright (c) 2022 American Academy of Neurology 


\section{Reader Response: Long-term Effect of Regular Physical Activity and Exercise Habits in Patients With Early Parkinson Disease}

Vinod K. Gupta (New Delhi)

Neurology ${ }^{\circledR}$ 2022;99:133. doi:10.1212/WNL.0000000000200924

Tsukita et al. ${ }^{1}$ emphasize the value of regular physical activity and exercise habits for improving the clinical course of Parkinson disease (PD), with each type of physical activity offering different benefits. Their study also recommends a change in attitude toward exercise as a therapy.

In the absence of further evolution of the interrelated pathophysiologic processes linked to PD, exercise (like stress) remains a mechanistic euphemism. ${ }^{2}$ The greater the lack of clarity on related alteration of pathophysiologic mechanisms, the more attractive the therapeutic role for exercise (high/low impact) becomes. ${ }^{2,3}$ Even randomized controlled trials or meta-analyses including exercise do not supplant the need for the therapy to be placed in a biologically plausible, overarching theoretical matrix. ${ }^{3,4}$ In order for exercise to emerge as a scientifically valid therapy for nonmotor and motor symptoms of $\mathrm{PD}$, it is essential to maintain hyperfocus on toxicity and the spread of $\alpha$-synuclein.

Motivation is a key factor for evaluating benefits of staying physically active in health and disease. ${ }^{5}$ Basal and stimulated motivation for exercise varies widely between individuals. Comparison of a cohort of patients with PD with and without the motivation profile for a particular physical exercise is important to critically differentiate the value of such therapy. ${ }^{5}$

1. Tsukita K, Sakamaki-Tsukita H, Takahashi R. Long-term effect of regular physical activity and exercise habits in patients with early Parkinson disease. Neurology. 2022;98(8):e859-e871. doi: 10.1212/WNL.0000000000013218

2. Gupta VK. Pathophysiology of migraine: an increasingly complex narrative to 2020. Future Neurol. 2019;14(2). doi: 10.2217/fnl-20190003

3. Barber M, Pace A. Exercise and migraine prevention: a review of the literature. Curr Pain Headache Rep. 2020;24(8):39. doi: 10.1007/ s11916-020-00868-6

4. Gupta VK. Patent foramen ovale closure and migraine: science and sensibility. Expert Rev Neurother 2010;10(9):1409-1422. doi: $10.1586 /$ ern. 10.125

5. Ferri-Caruana A, Millán-González L, García-Massó X, Pérez-Nombela S, Pellicer-Chenoll M, Serra-Añó P. Motivation to physical exercise in manual wheelchair users with paraplegia. Top Spinal Cord Inj Rehabil. 2020;26(1):1-10. doi: 10.1310/sci2601-01

Copyright $\odot 2022$ American Academy of Neurology

\section{Author Response: Long-term Effect of Regular Physical Activity and Exercise Habits in Patients With Early Parkinson Disease}

Kazuto Tsukita (Kyoto, Japan), Haruhi Sakamaki-Tsukita (Kyoto, Japan), and Ryosuke Takahashi (Kyoto, Japan) Neurology ${ }^{\circledR}$ 2022;99:133-134. doi:10.1212/WNL.0000000000200925

We thank Dr. Gupta for the comment on our article, ${ }^{1}$ which requested further elucidation of the biological basis of the effect of exercise, especially in relation to $\alpha$-synuclein toxicity. ${ }^{2}$ The comment also highlighted the importance of motivation for continued engagement in physical activities. The results of our study support the long-term effects of exercise, although the possibility of reverse causality cannot be denied. Whether these effects are "symptomatic" or "disease-modifying" warrants further studies in future. In this respect, further clinical trials with a delayed-start design, imaging studies exploring changes in the brain network after exercise, and animal studies exploring the effect of exercise on disease-relevant changes in Parkinson disease (PD) including $\alpha$-synuclein pathology are important. ${ }^{3-5}$

In addition, we believe that future research should clarify the impact of different motivations for exercise in the course of PD and strategies to support long-term motivation of patients with PD, 
for example, through remote supervision using mobile applications. We hope that further research in this direction will eventually lead to the establishment of strategies that enable patients with PD to live better lives through physical activity and exercise.

1. Tsukita K, Sakamaki-Tsukita H, Takahashi R. Long-term effect of regular physical activity and exercise habits in patients with early Parkinson disease. Neurology. 2022;98(8):e859-e871. doi:10.1212/WNL.0000000000013218.

2. Tsukita K, Sakamaki-Tsukita H, Tanaka K, Suenaga T, Takahashi R. Value of in vivo $\alpha$-synuclein deposits in Parkinson's disease: a systematic review and meta-analysis. Mov Disord. 2019;34(10):1452-1463. doi:10.1002/mds.27794.

3. Rascol O. "Disease-modification" trials in Parkinson disease: target populations, endpoints and study design. Neurology. 2009;72(7 suppl):S51-S58. doi:10.1212/WNL.0b013e318199049e.

4. Mak MK, Wong-Yu IS, Shen X, Chung CL. Long-term effects of exercise and physical therapy in people with Parkinson disease. Nat Rev Neurol. 2017;13(11):689-703. doi:10.1038/nrneurol.2017.128.

5. Espay AJ, Kalia LV, Gan-Or Z, et al. Disease modification and biomarker development in Parkinson disease: revision or reconstruction? Neurology. 2020;94(11):481-494. doi:10.1212/WNL.0000000000009107.

Copyright (c) 2022 American Academy of Neurology

CORRECTION \& REPLACEMENT

\section{Clinical Reasoning: A 57-Year-Old Man With Stepwise Progressive Paraparesis, Sensory Loss, Urinary Retention, and Constipation} Neurology ${ }^{\circledR}$ 2022;99:134. doi:10.1212/WNL.0000000000200703

In the Resident \& Fellow Section Clinical Reasoning article "A 57-Year-Old Man With Stepwise Progressive Paraparesis, Sensory Loss, Urinary Retention, and Constipation” by Alkabie et al., ${ }^{1}$ the in-text references to Figure 1 do not correlate with the figure's labels. The article has now been replaced by a corrected version with the figure references updated. The original version with the changes highlighted is available from a link in the corrected article. The editorial staff regret the errors.

\section{Reference}

1. Alkabie S, Tanweer O, Hutton GJ, Cuascut FX. Clinical Reasoning: A 57-year-old man with stepwise progressive paraparesis, sensory loss, urinary retention, and constipation. Neurology. 2022;98(5):e555-e560. 